\title{
Effects of epidermal growth factor on the growth and differentiation of cultured mouse ovarian follicles
}

\author{
N. I. Boland and R. G. Gosden \\ Department of Physiology, University Medical School, Teviot Place, Edinburgh EH8 9AG, UK
}

\begin{abstract}
The aim of this investigation was to determine the influence of epidermal growth factor (EGF) on follicular growth and steroidogenesis in mice. Follicles were cultured in medium containing human recombinant EGF at concentrations of $1-20 \mathrm{ng} \mathrm{ml}^{-1}$. Oestradiol production was assayed immunoenzymatically, and growth was measured by recording follicle diameter daily and by analysing the total DNA content of follicles. The effect of EGF on cumulus-oocyte complexes isolated from cultured follicles was also assessed. Results showed that EGF inhibited oestradiol production in a dose-dependent manner, but had no mitogenic effect. Despite almost complete inhibition of oestradiol production at concentrations of EGF $\geq 10 \mathrm{ng} \mathrm{ml}^{-1}$, follicles were still able to achieve preovulatory size and morphology, although the incidence of atresia was increased over controls. Conversely, at a concentration of only $1 \mathrm{ng} E G F \mathrm{ml}^{-1}$, a significantly greater number of follicles reached the Graafian stage compared with control follicles. Cumulus expansion and meiotic maturation by isolated cumulus-oocyte complexes from cultured follicles was dramatically stimulated in the presence of EGF and FSH, but not by FSH alone. These findings suggest that EGF may have a modulatory effect on oestradiol production in vivo, and that follicular growth and differentiation may be uncoupled from steroidogenesis. Finally, ovulatory changes in the cumulus-oocyte complex may require the presence of this factor.
\end{abstract}

\section{Introduction}

Epidermal growth factor (EGF) is a single-chain polypeptide, which has been shown to have a potent mitogenic effect on a variety of different cell types from a number of different species (for review, see Carpenter and Cohen, 1979). Most of the work that has been done on follicular cell responses to EGF has made use of granulosa monolayer cultures, in which the granulosa cells have been removed from interactions with other cell types (for reviews, see May and Schomberg, 1989; Ackland et al., 1992). Other work has focused on the short-term culture of hamster follicles that were isolated at different stages of development and maintained for only a few hours (Roy and Greenwald, 1991a, b; Roy, 1993a, b). All these studies have shown that the effects of EGF on granulosa cells are very diverse, and it has been suggested that EGF may have a paracrine role in follicular growth and differentiation.

New culture methods capable of supporting murine follicle development from preantral to preovulatory stages provide an opportunity to study the effects of EGF under more physiological conditions (for review, see Gosden et al., 1993). The following study describes the effects of EGF on follicular growth, morphology and steroidogenesis using a culture system modified for the study of murine follicle metabolism (Boland et al., 1993). Follicles were exposed to concentrations of human recombinant EGF ranging from 1 to $20 \mathrm{ng} \mathrm{ml}^{-1}$. The lower limit of the range represents the concentration of

Received 28 October 1993.
EGF that mouse follicles would normally be exposed to in vivo from the circulation (Byyny ef al., 1974). Higher concentrations were also tested because there is an increasing body of evidence that ovarian cells are sites of production of an EGF-like substance (Rall et al., 1985; Hsu et al., 1987; Hiramatsu et al., 1992), and concentrations of EGF between 10 and $20 \mathrm{ng}$ $\mathrm{ml}^{-1}$ have been recorded in porcine follicular fluid (Hsu et al., 1987).

In addition, unlike their counterparts in vivo, cumulusoocyte complexes isolated from cultured follicles exhibit a low incidence of cumulus expansion and first polar body formation in the presence of FSH, which may partly explain why attempts at fertilization have been unsuccessful. As EGF has been reported to stimulate cumulus expansion and meiotic maturation of cumulus-oocyte complexes isolated from mouse ovaries (Downs et al., 1988; Downs, 1989), a further study was undertaken to investigate its effect on cumulus-oocyte complexes from cultured follicles in the hope of improving maturation and facilitating subsequent fertilization.

\section{Materials and Methods}

\section{Animals}

Twenty-four-day old, prepubertal, $\mathrm{C} 57 \mathrm{BL} / 6 \times \mathrm{CBA} / \mathrm{ca} \mathrm{F}_{1}$ hybrid, female mice were housed in a room controlled for temperature and light on a $14 \mathrm{~h}$ light: $10 \mathrm{~h}$ dark photoperiod, and were given free access to food and water. 


\section{Follicle isolation and culture}

Mice were killed by cervical dislocation and their ovaries removed into watchglasses containing Leibovitz medium (L-15; Gibco-BRL, Irvine) at $37^{\circ} \mathrm{C}$. Preantral mouse follicles $180 \pm 10 \mu \mathrm{m}$ in diameter were isolated by microdissection using fine needles (Boland et al., 1993), and placed in $20 \mu \mathrm{l}$ of $\alpha$-minimal essential medium ( $\alpha$-MEM; Gibco-BRL) under $50 \mu \mathrm{l}$ mineral oil in the V-wells of a microtitre plate (Bibby-Sterilin Ltd, Staffs), according to the method of Boland et al. (1993). Medium was simplified from that originally published and contained only $\mathrm{I}$ iu human $\mathrm{FSH} \mathrm{ml} \mathrm{ml}^{-1}$ (hFSH: NIDDK, Bethesda, MD), $10 \mu \mathrm{g}$ human transferrin $\mathrm{ml}^{-1}$ (Sigma Chemical Co, Poole) and 5\% serum from hypogonadal (hpg:hpg) mice. The original supplements of pyruvate, glutamine and insulin were omitted as they are not required for normal follicle development in vitro (Boland et al., 1993, 1994; Spears et al., 1994).

\section{Experiment 1: effect of EGF on follicle development}

The culture medium was additionally supplemented with human recombinant EGF (1376454: Boehringer-Mannheim, Lewes) at $0,1,5,10$ and $20 \mathrm{ng} \mathrm{ml}^{-1}$. For each experiment, ten follicles were cultured in control medium (no EGF) and ten follicles in each of the EGF-treated groups (1-20 ng EGF $\mathrm{ml}^{-1}$ ). Every $24 \mathrm{~h}$, follicles were transferred to fresh wells of medium, and $5 \mu \mathrm{l}$ of media from the previous day's incubation was sampled for oestradiol (see below). Follicle growth and morphology were also assessed every $24 \mathrm{~h}$. On day 5 of culture, two representative preovulatory follicles were removed for histology from each control and EGF-treated group. The remaining antral follicles were enzymatically digested for measurement of DNA content (see below). Each experiment was repeated four times.

\section{Experiment 2: effect of EGF on cumulus expansion and meiotic maturation of cumulus-oocyte complexes from cultured follicles}

Fifty follicles were cultured as described above except that EGF was omitted from the culture medium. Follicles were transferred to fresh medium every $24 \mathrm{~h}$ and follicle growth was measured using a calibrated grid. On day 5 of culture, follicles were ruptured using fine needles and the cumulus-oocyte complexes removed. The cumulus-oocyte complexes were then divided into two groups and cultured overnight at $37^{\circ} \mathrm{C}$ in $\alpha$-MEM containing 1 iu hFSH ml ${ }^{-1}, 10 \mu \mathrm{g}$ transferrin $\mathrm{ml}^{-1}$ and $5 \%$ fetal calf serum with or without $10 \mathrm{ng}$ EGF $\mathrm{ml}^{-1}$.

The following day, germinal vesicle breakdown and first polar body formation were scored, and cumulus expansion was measured subjectively according to the criteria described by Vanderhyden et al. (1990). A score of 0 was given for cumulus-oocyte complexes with completely compacted cumulus cells that formed a monolayer on the surface of the culture dish; + I for the minimum observable response to EGF, which was no monolayer formation and cumulus-oocyte complexes with a glistening appearance; +2 for cumulus-oocyte complexes with an expanded outer layer of cells; +3 for expansion of all layers except the corona radiata; and +4 for cumulusoocyte complexes exhibiting fully expanded and mucified cumulus cells, including the corona radiata. Both groups of cumulus-oocyte complexes (with and without EGF) were scored 'blind' by the same investigator after covering the lids of the culture dishes and assigning codes ' $\mathrm{A}$ ' and ' $\mathrm{B}$ ' randomly. After scoring, the codes were checked against the experimental treatment and the procedure was repeated twice after shuffling the culture dishes.

\section{Steroidogenesis}

Oestradiol production was measured immunoenzymatically for individual follicles on each day of culture using a Serozyme II photometer (Serono Diagnostics, Woking) and oestradiol assay kit (sensitivity $\geq 18 \mathrm{pmol} \mathrm{I}^{-1}$ ) according to the manufacturer's instructions. The interassay and intra-assay coefficients of variation were $\leq 5 \%$.

\section{Follicle growth and morphology}

The number of preovulatory follicles and the total number of antral stages were recorded at the end of each culture. Preovulatory follicles were classified as having (i) a diameter $\geq 400 \mu \mathrm{m}$, (ii) a large antral cavity, (iii) an acentrically placed cumulus-oocyte complex, and (iv) no signs of atresia (visible as dark patches of dead cells within the membrana granulosa). Antral follicles included all follicles with a clearly defined antral cavity of any size and no signs of atresia in the membrana granulosa.

Follicle growth was monitored in two ways: (i) measuring follicle diameter on each day of the culture using a precalibrated ocular micrometer at $\times 40$ magnification; or (ii) by assessing DNA accumulation in non-atretic, preovulatory follicles on day 5 with a fluorochrome dye, Hoechst 33258 (bisbenzimidazole; Sigma Chemical Co), and a Dynatech 'Microfluor' automatic microplate fluorescence reader $(365 \mathrm{~nm}$ excitation, $450 \mathrm{~nm}$ emission; Dynatech, Billingshurst), using a method modified from West et al. (1985).

For measurement of DNA, follicles were washed in two changes of double-distilled, deionized water and placed individually in $50 \mu \mathrm{l}$ of $10 \times$ trypsin solution $\left(25 \mathrm{mg} \mathrm{m}^{-1}\right.$; Sigma Chemical $\mathrm{Co}$ ) in the U-wells of a microtitre plate (BibbySterilin). The follicles in each well were then crudely teased apart with needles and incubated at $37^{\circ} \mathrm{C}$. After $60 \mathrm{~min}$ of digestion, the contents of each well were pipetted up and down three times to break up the cells and the plate was then returned to the incubator for a further $15 \mathrm{~min}$. Digestion was stopped with $50 \mu \mathrm{l}$ of trypsin inhibitor $\left(4.4 \mathrm{mg} \mathrm{m}^{-1}\right.$ in double-distilled deionized water) and wells were adjusted to a final $\mathrm{pH}$ of 7.0 using $100 \mu \mathrm{l}$ of alkaline double-distilled deionized water (with $\mathrm{pH}$ adjusted to 11.2 using $\mathrm{NaOH}$ ). The contents of each well $(200 \mu \mathrm{l})$ were then mixed thoroughly before being transferred to a 96-well, white-background plate (Dynatech). Ten wells containing $100 \mu \mathrm{l}$ double-distilled

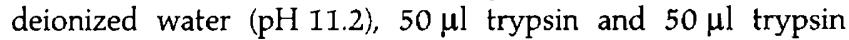
inhibitor acted as the negative control to quantify background fluorescence.

A second plate was set up with $100 \mu$ standards of salmon testes DNA (Type III; Sigma Chemical Co) diluted to give a 


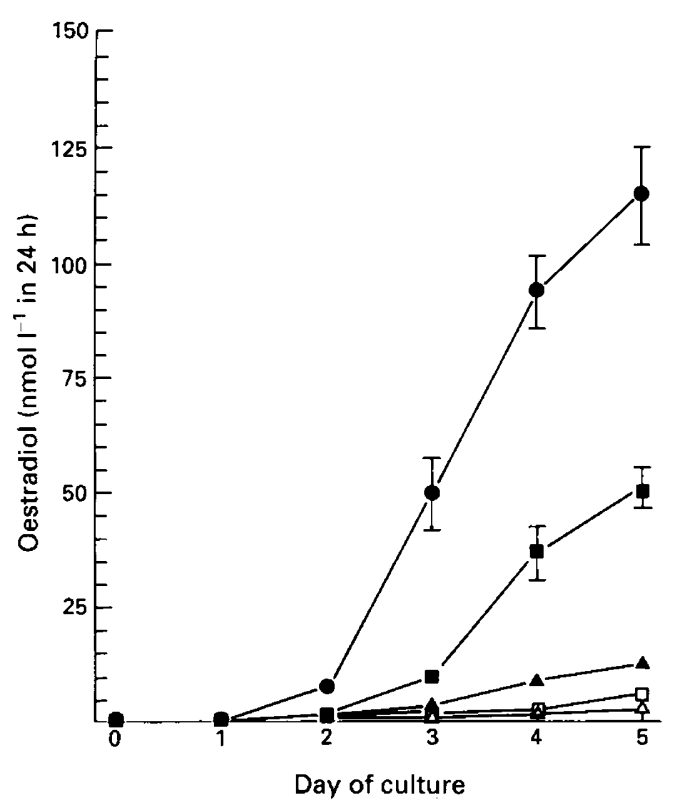

Fig. 1. Oestradiol profiles for mouse follicles cultured in (๑) control

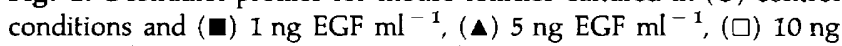
EGF $\mathrm{ml}^{-1}$, and $(\triangle) 20 \mathrm{ng} \mathrm{EGF} \mathrm{ml}^{-1}$.

range of concentrations from 0 to $1000 \mathrm{ng}$ per $100 \mu \mathrm{l}$ doubledistilled deionized water. The volume of each well was then made up to $200 \mu \mathrm{l}$ with a mixture of $100 \mathrm{mmol} \mathrm{NaCl} 1^{-1}$ and $10 \mathrm{mmol} \mathrm{Tris} \mathrm{1}^{-1}$ (pH 7.0). Ten wells containing $100 \mu \mathrm{l}$ double-distilled deionized water and $100 \mu \mathrm{l} \mathrm{NaCl}$-Tris buffer acted as a negative control for the DNA standards. A stock solution of $200 \mu \mathrm{g}$ Hoechst $33258 \mathrm{ml}^{-1}$ (Sigma Chemical Co) was diluted 1:500 with $\mathrm{NaCl}-$ Tris buffer $(\mathrm{pH} \mathrm{7.0)}$ ), and $50 \mu \mathrm{l}$ was pipetted rapidly into each well containing the digested follicles, negative controls and DNA standards. The final volume of each well was $250 \mu \mathrm{I}$ and the final $\mathrm{pH}$ of the wells was 7.0, which is the optimum $\mathrm{pH}$ for Hoechst dye fluorescence. Measurements of fluorescence for individual follicles were converted to nanograms of DNA by extrapolation from the salmon testes DNA calibration curve after subtraction of the reagent blank fluorescence values.

\section{Histology}

Follicles were fixed in 5\% paraformaldehyde overnight, dehydrated through a graded series of ethanol concentrations and then embedded in 2-hydroxyethylmethacrylate resin (Sigma Chemical Co). Blocks were sectioned at a thickness of $1 \mu \mathrm{m}$ on to polylysine-coated slides, and stained with haematoxylin and eosin before mounting.

\section{Statistical analysis}

Probability values ( $P$ value) between the different groups were determined by the unpaired Student's $t$ test and the Kruskal-Wallis ANOVA.

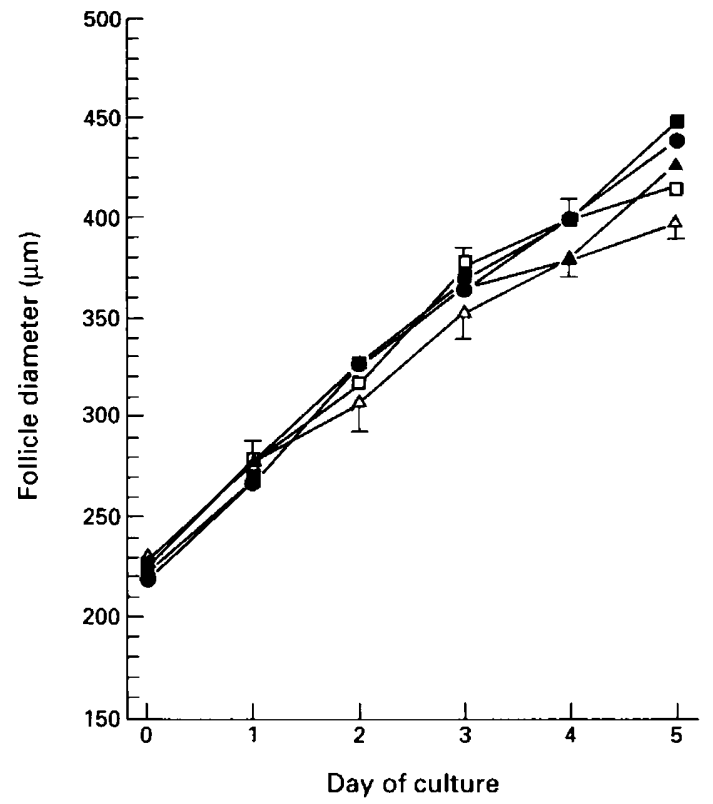

Fig. 2. Growth profiles for mouse follicles cultured in (-) control conditions, and in (ロ) $1 \mathrm{ng} \mathrm{EGF} \mathrm{ml}^{-1},(\Delta) 5 \mathrm{ng} \mathrm{EGF} \mathrm{ml}^{-1}$, (口) $10 \mathrm{ng}$ $\mathrm{EGF} \mathrm{\textrm {ml } ^ { - 1 }}$, and $(\triangle) 20 \mathrm{ng} \mathrm{EGF} \mathrm{ml}^{-1}$.

\section{Results}

\section{Experiment 1: effect of EGF on follicle development}

Steroidogenesis. Epidermal growth factor caused a dosedependent decline in oestradiol production over the 5-day culture (Fig. 1). A concentration of only $1 \mathrm{ng}$ EGF $\mathrm{ml}^{-1}$ significantly reduced oestradiol production to approximately half that of control follicles (control, $115 \pm 10 \mathrm{nmol}$ oestradiol $\mathrm{I}^{-1}$ in $24 \mathrm{~h} ; \mathrm{Ing}$ EGF $\mathrm{ml}^{-1}, 51 \pm 7 \mathrm{nmol}$ oestradiol $\mathrm{I}^{-1}$ in $24 \mathrm{~h}$ on day 5 of culture; $P<0.001$ for days $2-5$ ). At $5 \mathrm{ng} \mathrm{ml} \mathrm{ml}^{-1}$, EGF severely inhibited oestradiol production (12.7 $\pm 1 \mathrm{nmol}$ oestradiol $\mathrm{I}^{-1}$ in $24 \mathrm{~h}$ on day 5; $P<0.001$ for days 2-5), and between 10 and $20 \mathrm{ng} \mathrm{ml}^{-1}$, production was only just detectable $(6.1 \pm 0.3$ and $3.3 \pm 0.1 \mathrm{nmol}$ oestradiol $\mathrm{I}^{-1}$ in $24 \mathrm{~h}$ on day 5, respectively; $P<0.001$ for days $2-5)$.

Growth and morphology. There was no significant difference in diameter between control follicles and those cultured in the presence of 1 and $5 \mathrm{ng}$ EGF $\mathrm{ml}^{-1}(P>0.05$ for each day of culture; Fig. 2). However, follicles cultured with 10 and

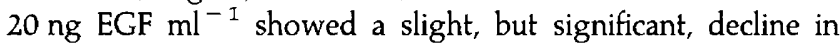
diameter on day 5 of culture compared with control follicles (control, $439 \pm 7 \mu \mathrm{m} ; 10 \mathrm{ng}$ EGF ml ${ }^{-1}, 416 \pm 8 \mu \mathrm{m}, P<0.05$; $20 \mathrm{ng}$ EGF $\mathrm{ml}^{-1}, 398 \pm 7 \mu \mathrm{m}, P<0.02$ ). The absence of any EGF-stimulated increase in follicle growth was supported by the finding that there was no significant difference in the DNA content of control follicles on day 5 and those cultured with EGF at concentrations ranging from 1 to $20 \mathrm{ng} \mathrm{ml}^{-1}$ when analysis of variance was determined by the KruskalWallis test $(P>0.1$; Table 1$)$. Freshly isolated follicles had a DNA content of only $30 \pm 2 \mathrm{ng}$, demonstrating the capability of the system to sustain cell proliferation. The DNA 
Table 1. Amount of DNA in mouse follicles after 5 days of culture in different concentrations of EGF

\begin{tabular}{lccccc}
\hline & \multicolumn{5}{c}{ Concentration of EGF (ng ml ${ }^{-1}$ ) } \\
\cline { 2 - 6 } & 0 & 1 & 5 & 10 & 20 \\
\hline Amount of DNA in follicles & $580 \pm 46$ & $610 \pm 51$ & $640 \pm 35$ & $670 \pm 32$ & $585 \pm 64$ \\
\hline
\end{tabular}

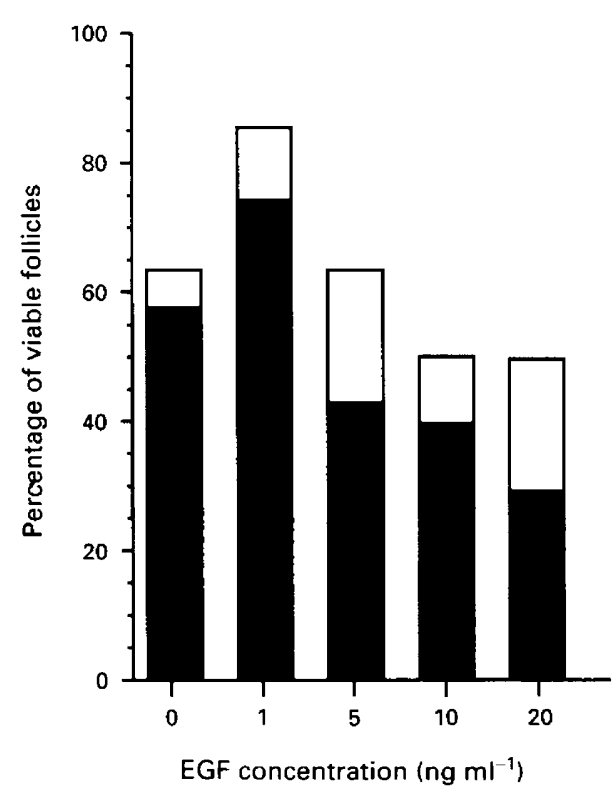

Fig. 3. Percentage of healthy antral $(\square)$ and preovulatory ( $\square$ ) mouse follicles on day 5 of culture in control and epidermal growth factor (EGF)-treated groups.

calibration curve was linear from 10 to $1000 \mathrm{ng}$ DNA and the intra-assay and interassay coefficients of variation were $<5 \%$.

Follicles in all of the EGF-stimulated groups were able to reach the terminal stages of development and exhibited normal Graafian morphology despite attenuation of oestradiol production. However, EGF appeared to have a biphasic effect on the rate of follicle atresia (Fig. 3). At a concentration of $1 \mathrm{ng} \mathrm{ml}^{-1}$, EGF had increased the number of antral and Graafian follicles by the end of the culture period compared with control groups $(P<0.01$ and $P<0.05$, respectively). Conversely, at higher concentrations of EGF, the number of antral follicles was significantly reduced compared with controls $(P<0.01$ for 10 and $20 \mathrm{ng}$ EGF $\mathrm{ml}^{-1}$ ), and at a concentration of $20 \mathrm{ng}$ EGF $\mathrm{ml}^{-1}$, there was also a decline in the number of Graafian follicles $(P<0.05)$. However, there was no difference in the total number of follicles at the antral and Graafian stages cultured in control conditions and in those cultured with $5 \mathrm{ng}$ EGF $\mathrm{ml}^{-1}$ ( $P>0.5$ and $P>0.2$, respectively) (Fig. 3). Light microscopy showed that the morphology of follicles reaching the Graafian stages of development was similar among all the experimental groups and there were few, if any, cells that could be described as atretic.
Experiment 2: effect of EGF on cumulus expansion and meiotic maturation of cumulus-oocyte complexes isolated from cultured follicles

Cumulus-oocyte complexes cultured in the presence of $10 \mathrm{ng}$ EGF ml ${ }^{-1}$ overnight were significantly more expanded and mucified than were cumulus-oocyte complexes cultured in the presence of $\mathrm{FSH}$ alone $(P<0.001)$. Although the incidence of germinal vesicle breakdown was similar between the two groups $(P>0.05)$, first polar body formation was significantly higher in the EGF-treated group $(P<0.001)$ (Table 2$)$.

\section{Discussion}

Previous studies with granulosa cell monolayer cultures from humans (Steinkampf et al., 1988; Mason et al., 1990), pigs (Hiramatsu et al., 1992) and rats (Hsueh et al., 1981) have shown that EGF inhibits oestradiol production. This finding has been confirmed in mice under more physiological conditions by the present study, which shows that EGF causes a dosedependent decline in oestradiol production by isolated follicles developing in vitro. Murine ovarian follicles would normally be exposed to $1.2 \pm 0.2 \mathrm{ng} \mathrm{EGF} \mathrm{ml}^{-1}$ from the circulation (Byyny et al., 1974). A concentration of approximately $1 \mathrm{ng} \mathrm{ml} \mathrm{m}^{-1}$ (including the serum contribution) reduces oestradiol production by cultured follicles to almost half that of control values, suggesting that follicular oestradiol production could be modulated by EGF in vivo.

Although follicles probably come into contact with EGF through the blood stream, the mouse ovary is also thought to be a site of EGF synthesis (Rall et al., 1985), and concentrations of $>10 \mathrm{ng} \mathrm{ml}^{-1}$ have been detected in the follicular fluid of other species (Hsu et al., 1987). The present study demonstrates that there is a significant decline in the number of cultured follicles reaching the antral stages of development above a concentration of $5 \mathrm{ng} \mathrm{EGF} \mathrm{ml}^{-1}$. In pigs, the concentration of EGF is higher in the follicular fluid of small antral follicles than it is in the larger Graafian types (13.6 \pm 1 and $<6 \mathrm{ng} \mathrm{ml}^{-1}$, respectively; Hsu et al., 1987), and, as the majority of small antral follicles become atretic in vivo ( $>99 \%$ ), it is possible that high concentrations of EGF in the follicular fluid may reflect incipient atresia. Despite high concentrations of EGF favouring atresia, low concentrations appear to enhance antral development, indicating that EGF may have a biphasic effect on follicle survival.

It has been shown that mouse follicles can grow to preovulatory sizes in a concentration of FSH (100 miu ml $\left.{ }^{-1}\right)$ that is insufficient to stimulate more than transient oestradiol production (Nayudu and Osborn, 1992). The present study confirms 
Table 2. Maturation of mouse cumulus-oocyte complexes isolated from antral follicles grown in vitro and cultured with or without $10 \mathrm{ng}$ EGF ml ${ }^{-1}$

\begin{tabular}{lccc}
\hline Culture conditions & $\begin{array}{c}\text { Cumulus expansion } \\
\text { (score 3-4) }\end{array}$ & $\begin{array}{c}\text { Germinal vesicle } \\
\text { breakdown }\end{array}$ & $\begin{array}{c}\text { First polar body } \\
\text { formation }\end{array}$ \\
\hline Control & $0 / 19(0 \%)$ & $18 / 19(95 \%)$ & $6 / 19(32 \%)$ \\
EGF $\left(10 \mathrm{ng} \mathrm{ml}^{-1}\right)$ & $19 / 19(100 \%)$ & $19 / 19(100 \%)$ & $17 / 19(90 \%)$ \\
\hline
\end{tabular}

this finding by demonstrating that at high concentrations of FSH ( 1 iu ml ${ }^{-1}$ ) normal follicular oestradiol production can be almost completely inhibited by EGF without preventing preovulatory development. The observation that normal follicular growth and differentiation can be uncoupled from oestradiol synthesis supports the findings from a number of studies, which have indicated that this steroid may not be as important within the ovary as was originally thought. It was reported that follicle development and ovulation could be achieved in gonadotrophin-deficient women given recombinant FSH, despite low concentrations of oestradiol in the serum of these patients (Schoot et al., 1992). Subsequently, Uilenbroek et al. (in press) demonstrated the same phenomenon in hypophysectomized rats.

Despite the dramatic inhibitory action of EGF on steroidogenesis, this growth factor does not appear to have an obvious mitogenic effect on mouse follicular cells. Although this finding is inconsistent with the behaviour of ovarian cells from a number of other species (Gospodarowicz et al., 1977; Gospodarowicz and Bialecki, 1979), the granulosa cells of both guinea-pigs and rats also fail to proliferate in response to EGF (Gospodarowicz and Bialecki, 1979).

In addition to the effects of EGF on developing follicles in vitro, isolated cumulus-oocyte complexes from cultured follicles exhibit a large capacity for cumulus expansion and a high rate of meiotic maturation to the first polar body stage when cultured in the presence of this growth factor. This finding is in agreement with previous work that showed that EGF can promote cumulus cell expansion and oocyte maturation in cumulus-oocyte complexes isolated from mouse ovaries (Downs, 1989). However, unlike isolated cumulus-oocyte complexes grown in vivo, the cumulus-oocyte complexes from follicles grown in vitro achieved only a low rate of first polar body formation and completely failed to undergo cumulus expansion when cultured with FSH in the absence of EGF. This point is important because, under normal conditions, $\mathrm{FSH}$ alone should be able to stimulate the expansion of mouse cumulusoocyte complexes as long as serum is also present (Eppig 1979a, b; 1980; Schroeder and Eppig, 1984; Salustri et al., 1989; Chen et al., 1990). The inability of FSH to induce expansion and oocyte maturation in the cumulus-oocyte complexes from the cultured follicles suggests a role for EGF in preparing the oocyte for ovulation and fertilization, a possibility that Downs et al. (1988) have already alluded to. As it is likely that mouse follicles are exposed to EGF in vivo (Byyny et al., 1974; Rall et al., 1985), the absence of adequate EGF under follicle culture conditions could, perhaps, explain why attempts at oocyte fertilization have been unsuccessful in the past. Subsequent to this observation, we have demonstrated that the oocytes from follicles grown in vitro are not only fertile, but have the capacity to be fertilized and produce live pups when cultured in the presence of EGF before insemination (Spears et al., 1994).

In summary, EGF has been shown to have a profound modulatory effect on follicular steroidogenesis in mice at physiological concentrations, but a mitogenic role for this growth factor in the mouse follicle was not observed. At the blood plasma concentration, EGF caused a decline in oestradiol production but increased the number of follicles reaching the antral and Graafian stages of development. At higher concentrations, oestradiol production was severely attenuated, but follicles still continued to grow to the preovulatory stage, although the incidence of atresia was increased. The ability of cumulus-oocyte complexes isolated from cultured follicles to expand and undergo high rates of meiotic maturation in the presence of EGF, but not in the presence of FSH alone, indicates that this factor could influence oocyte fertility. Together, these findings provide further evidence to suggest that EGF has a role during follicular development and oocyte maturation in vivo.

This work was generously supported by a Wellcome Trust Prize Fellowship. We gratefully acknowledge the gifts of hFSH and hLH from the National Institute of Diabetes and Digestive and Kidney Diseases (NIDDK), part of the National Hormone and Pituitary Program. Thanks go to G. Curry, Department of Geology, University of Glasgow, for kindly allowing the use of his Dynatech fluorescent plate reader, and to the Medical Microbiology Transgenic Unit, University of Edinburgh for supplying the mice.

\section{References}

Ackland JF, Schwartz NB, Mayo KE and Dodson RE (1992) Nonsteroidal signals originating in the ovary Physiological Reviews 72 731-787

Boland NI, Humpherson PG, Leese HJ and Gosden RG (1993) Pattern of lactate production and steroidogenesis during growth and maturation of mouse ovarian follicles in vitro Biology of Reproduction 48 798-806

Boland NI, Humpherson PG, Leese HJ and Gosden RG (1994) The effect of glucose metabolism on murine follicle development and steroidogenesis in vitro Human Reproduction 9 617-623

Byyny RL, Orth DN, Cohen S and Doyne ES (1974) Epidermal growth factor: Effects of androgens and adrenergic agents Endocrinology 95 776-782

Carpenter G and Cohen S (1979) Epidermal growth factor Annual Reviews of Biochemistry 48 193-216

Chen L, Wert SE, Hendrix M, Russell PT, Cannon M and Larsen WJ (1990) Hyaluronic acid synthesis and gap junction endocytosis are necessary for normal expansion of the cumulus mass Molecular Reproduction and Development 26 236-247

Downs SM (1989) Specificity of epidermal growth factor action on maturation of the murine oocyte and cumulus oophorus in vitro Biology of Reproduction 41 371-379 
Downs SM, Daniel SAJ and Eppig JJ (1988) Induction of maturation in cumulus cell-enclosed mouse oocytes by follicle-stimulating hormone and epidermal growth factor: Evidence for a positive stimulus of somatic cells origin The Journal of Experimental Zoology 245 86-96

Eppig JJ (1979a) FSH stimulates hyaluronic acid synthesis by oocyte-cumulus cell complexes from mouse preovulatory follicles Nature 281 483-484

Eppig JJ (1979b) Gonadal stimulation of the expansion of cumulus oophori isolated from mice: General conditions for expansion in vitro Journal of Experimental Zoology 208 111-120

Eppig JJ (1980) Regulation of cumulus oophorus expansion by gonadotropin in vivo and in vitro Biology of Reproduction 23 545-552

Gosden RG, Boland NI, Spears N, Murray AA, Chapman M, Wade JC, Zhody NI and Brown N (1993) The biology and technology of follicular oocyte development in vitro Reproductive Medicine Reviews 2 129-152

Gospodarowicz D and Bialecki H (1979) Fibroblast and epidermal growth factors are mitogenic agents for cultured granulosa cells of rodent, porcine and human origin Endocrinology 104 757-865

Gospodarowicz D, III CR and Birdwell CR (1977) Effects of fibroblast and epidermal growth factors on ovarian cell proliferation in vitro. I. Characterization of the response of granulosa cells to FGF and EGF Endocrinology 100 1108-1120

Hiramatsu S, Maruo T, Matsuo H and Mochizuki M (1992) Effects of epidermal growth factor on the proliferation and differentiation of porcine granulosa cells cultured in vitro Acta Obstetrics and Gynaecology Japan 44 55-61

Hsu C-J, Holmes SD and Hammond JM (1987) Ovarian epidermal growth factor-like activity: concentrations in porcine follicular fluid during follicular enlargement Biochemical and Biophysical Research Communications $147242-$ 247

Hsueh AJW, Welsh TH and Jones PBC (1981) Inhibition of ovarian and testicular steroidogenesis by epidermal growth factor Endocrinology 108 2002-2004

Mason HD, Margara R, Winston RML, Beard RW, Reed MJ and Franks S (1990) Inhibition of oestradiol production by epidermal growth factor in human granulosa cells of nomal and polycystic ovaries Clinical Endocrinology 33 $511-517$

May JV and Schomberg DW (1989) The potential relevance of epidermal growth factor and transforming growth factor- $\alpha$ to ovarian physiology Seminars in Reproductive Endocrinology 7 1-11

Nayudu PL and Osborn SM (1992) Factors influencing the rate of preantral and antral growth of mouse ovarian follicles in vitro Joumal of Reproduction and Fertility 95 349-362

Rall LB, Scott J, Bell GI, Crawford RJ, Penschow JD, Niall HD and Coghlan JP (1985) Mouse prepro-epidermal growth factor synthesis by the kidney and other tissues Nature 313 228-231

Roy SK (1993a) Transforming growth factor- $\beta$ potentiation of folliclestimulating hormone-induced deoxyribonucleic acid synthesis in hamster preantral follicles is mediated by a latent induction of epidermal growth factor Biology of Reproduction 48 558-563
Roy SK (1993b) Epidermal growth factor and transforming growth factor- $\beta$ modulation of follicle-stimulating hormone-induced deoxyribonucleic acid synthesis in hamster preantral and early antral follicles Biology of Reproduction $48 \quad 552-557$

Roy SK and Greenwald GS (1991a) Mediation of follicle-stimulating hormone action on follicular deoxyribonucleic acid synthesis by epidermal growth factor Endocrinology 129 1903-1908

Roy SK and Greenwald GS (1991b) In vitro effects of epidermal growth factor, insulin-like growth factor-I, fibroblast growth factor and follicle-stimulating hormone on hamster follicular deoxyribonucleic acid synthesis and steroidogenesis Biology of Reproduction 44 889-896

Salustri A, Yanagishita M and Hascall VC (1989) Synthesis and accumulation of hyaluronic acid and proteoglycans in the mouse cumulus cell-oocyte complex during follicle-stimulating hormone-induced mucification Journal of Biological Chemistry 26413 840-13 845

Schoot DC, Coellingh Bennink HJT, Mannaerts BMJL, Lamberts SWJ, Bouchard P and Fauser BCJM (1992) Human recombinant follicle-stimulating hormone induces growth of preovulatory follicles without concomitant increase in androgen and oestrogen biosynthesis in a woman with isolated gonadotrophin deficiency Joumal of Clinical and Endocrinological Metabolism 74 1471-1473

Schroeder AC and Eppig JJ (1984) The developmental capacity of mouse oocytes that matured spontaneously in vitro is normal Developmental Biology $102493-497$

Spears N, Boland NI, Murray AA and Gosden RG (1994) Oocytes from cultured mouse ovarian follicles are fertile Human Reproduction 9 527-532

Steinkampf MP, Mendelson CR and Simpson ER (1988) Effects of epidermal growth factor and insulin-like growth factor I on the levels of mRNA encoding aromatase cytochrome P-450 of human granulosa cells Molecular and Cellular Endocrinology 59 93-99

Uilenbroek JTJ, Mannaerts B and de Leeuw R Follicular development in hypophysectomized immature rats after treatment with recombinant human FSH. Proceedings of the 8th Reinier de Graaf Symposium, Amsterdam. The Netherlands Eds J Schoemaker and R Schats. Parthenon Publishing, London. (in press)

Vanderhyden BC, Caron PJ, Buccione R and Eppig JJ (1990) Developmental pattern of the secretion of cumulus-expansion enabling factor by mouse oocytes and the role of oocytes in promoting granulosa cell differentiation Developmental Biology 140 307-317

West DC, Sattar A and Kumar S (1985) A simplified in situ solubilization procedure for the determination of DNA and cell number in tissue cultured and mammalian cells Analytical Biochemistry 147 289-295 